\title{
Lixo, identidade e trabalho: a construção da identidade dos catadores de materiais recicláveis associados de Goiânia
}

\author{
Marina Roriz Rizzo Lousa da Cunha \\ Mestre em Sociologia (Universidade Federal de Goiás) \\ Professora na Universidade Federal de Goiás \\ marinaroriz@hotmail.com
}

\begin{abstract}
Resumo
$\mathrm{Na}$ atualidade, diante de um mercado de trabalho excludente, várias são as estratégias de sobrevivência adotadas pelos grupos sociais com menor qualificação. Dentre aqueles que se encontram nessa situação, podemos mencionar a realidade dos catadores de materiais recicláveis. Para este grupo, que vive das latas de lixo, local onde podemos encontrar os principais e mais abundantes bens de nosso tempo, os descartes do consumo, mas ao mesmo tempo, representa o local dos rejeitados e excluídos, lugar em que ninguém quer estar, uma situação particular é delineada. É ali que estes trabalhadores, sujeitos a uma identidade social deteriorada, encontram uma forma lícita de sobreviver, de construir sua identidade e almejar reconhecimento social. Este trabalho apresenta como este processo vem se estabelecendo e como este grupo, em especial, tem tentado, valendo-se de formações coletivas, promover sua distinção como grupo social legítimo.
\end{abstract}

Palavras-chave: formação de identidade; associativismo; lixo; trabalho; grupos sociais.

$\mathrm{N}$ A transição do século XX para o XXI, ricos e pobres são afetados por transformações das mais diversas maneiras e intensidades. É a modernidade tardia, que Beck considera uma fase em que a modernidade é inserida num novo modelo social que mina e revisa as características do momento anterior, industrial, e que abre o projeto humano para novas contingências, complexidades e incertezas.

Entre essas, a modernidade tardia marca uma fase de transformações no jeito de viver das pessoas. Contemporaneamente, Bauman acredita que o estilo de vida é caracterizado pela precariedade, marcada por condições de incerteza constante, pela transitoriedade e alterações sucessivas em suas formas. É uma vida líquida, em que o existir significa transformar-se constantemente, numa verdadeira sucessão de reinícios.

Esta vida líquida (Bauman, 2007) marca uma sociedade balizada por valores voláteis, instáveis, descompromissados com o futuro, egoístas e hedonistas. Valores estes que acabam por gerar preceitos e ligações frouxas, além de compromissos revogáveis.

Muda-se o modelo social, alteram-se o jeito de viver e os valores. Em consequência, acredita Bauman, nestes cenários se reestruturam os processos de formação identitários baseados em referências em movimento, marcadas por grupos móveis, frágeis e velozes, que buscam desesperadamente âncoras sociais com as quais possam se referenciar momentaneamente, e onde "as identidades ao estilo antigo [...] simplesmente não funcionam" (Bauman, 2005a, p. 33). Um modelo identitário caracterizado por ganhar livre curso, cabendo a cada indivíduo fazer suas escolhas, a partir dos recursos e ferramentas que tem disponível. 
Dentre esses recursos, o consumo estabelece-se como matéria-prima contínua e obsessiva para dar forma às identidades. Consumir, nesse sentido, mais do que tratar do consumo de signos, passa a funcionar como um elemento que avalia e julga as pessoas, chegando a estruturar e orientar todo o ambiente social por uma "síndrome consumista" (Bauman, 2001, p. 109). O consumo modela a tudo e a todos.

Os bens de consumo passam também a configurar uma situação original porque, pela primeira vez na história da humanidade, livrar-se das coisas se torna tão ou mais importante do que a mera posse. Como nesta sociedade a taxa de mortalidade de expectativas é elevada, consumidores experientes não se importam de destinar à lata de lixo tudo o que já tenha ultrapassado seu tempo de uso. E o descarte tem sentido próprio: é o medo de ser considerado out pela vida social, é o receio de ser jogado no lixo.

O lixo, portanto, tem papel especial nesse contexto. Por ser o produto principal e mais abundante desse tempo, resultado final de toda e qualquer ação de consumo, descartar tudo o que se tornou obsoleto é medida de satisfação, é garantia de estar fora do lugar onde ninguém quer estar.

Assim, o lixo é considerado o local dos excluídos e rejeitados, dos que possuem uma identidade social deteriorada (Goffman, 1988).

Neste modelo social descrito, alguns grupos vivem do lixo, entre eles agentes econômicos que se apropriam dos restos da sociedade para retirarem dali sua sobrevivência. São os catadores de materiais recicláveis. Um grupo complexo e diversificado e sujeito a profunda rejeição social.

$\mathrm{Na}$ tentativa de reverter esse processo, vários são os catadores que têm se unido em organizações que Beck nomeia de subpolíticas, como as associações e cooperativas de catadores de materiais recicláveis e movimentos nacionais, para lutar pela mudança de sua condição social, promover sua distinção como grupo social legítimo e ressignificar os sentidos originais que lhe são conferidos pelos padrões dominantes do consumismo e das identidades estabelecidas.

São formas alternativas de se lutar pelo reconhecimento social, que agora passam também a se dar pelos atores agindo por meio de sistemas políticos, grupos de interesse ou organizações políticas transnacionais ou por arenas, que se caracterizam pelos acordos e instituições internacionais (Beck, 2007).

Essas lutas alternativas por reconhecimento ganham novos formatos, sendo debatidas ao mesmo tempo em agendas políticas locais, regionais, nacionais e internacionais e resolvidas na esfera transnacional, nos casos em que se tornam incapazes de se enquadrar em modelos políticos nacionais.
A subpolitização se caracteriza pela perda da credibilidade das instituições que deveriam garantir os direitos básicos da população, tais como indústrias, economia, sistema legal, ciências, política e pelo aparecimento de instituições, atores e arenas organizados, de fora do sistema dos estados nacionais, que questionam o modelo central. Além disso, o debate político passa a envolver temas cotidianos que não estavam ligados ao espectro tradicional, como os problemas que evocam significados antes não conferidos ao lixo, no contexto do consumo, da liquidez, do risco, da sustentabilidade, da ocupação de grupos novos e específicos etc, isto é, de vários aspectos que revelam problemas e perdas de controle por parte das instituições símbolos da modernidade. A partir desse modelo, formam-se coalizões de opostos, capazes de alterar as regras e as características do modelo tradicional de política, tornando-o suscetível a novos links e à possibilidade de serem renegociados e remodelados (Beck, 2007). No caso dos catadores de materiais recicláveis nas maiores cidades brasileiras, essa realidade se torna mais visível a partir de meados de 1999, com o nascimento do Movimento Nacional dos Catadores de Materiais Recicláveis ${ }^{1}$ que luta para a valorização da categoria e o reconhecimento de sua importância frente à sociedade valendo-se de ações populares diretas e dispensando a fala de partidos políticos, governos e empresários em seu nome.

Uma alteração na configuração política como esta ocasiona a invasão dos atores para além das responsabilidades e hierarquias formais, chegando a espaços sociais antes inimagináveis, como o universo dos catadores de materiais recicláveis. Assim, quanto mais o processo capitalista avança, mais as áreas de tomada de decisão (setor privado, negócios, ciência, cidades, vida cotidiana etc.), tão protegidas no capitalismo industrial, são invadidas pelos conflitos políticos da modernidade tardia, isto é, tornam-se mais dependentes das decisões políticas. E este fator, somado à cultura individualizada do ocidente, que é marcada pela educação mais aprimorada e em maior escala, empregos e oportunidades melhores para se ganhar dinheiro e onde as pessoas não simplesmente obedeçam, possibilitam a individualização dos conflitos e também dos interesses políticos, que não podem ser sinônimo de desengajamento. Pelo contrário, surge um engajamento múltiplo, contraditório, nos diversos agrupamentos que se formam, misturando e combinando polos clássicos de política. Todos são esquerdistas e direitistas, radicais e conservadores, políticos e não políticos, ecológicos e não ecológicos, tudo ao mesmo tempo (Beck, 2007).

Subpolítica, nesta visão, representa modelar a sociedade de baixo para cima, o que resulta na perda 
do poder de implementação, encolhimento e minimização da política. Há, nela, oportunidades para que os mais diversos grupos sociais se façam ouvir e tenham participação na sociedade. Cidadãos, esfera pública, movimentos sociais, grupos especializados, trabalhadores no local de trabalho, todos podem ter oportunidades de "moverem montanhas nos centros estratégicos de desenvolvimento" (Beck, 2007, p. 36). Aqui, vários grupos e níveis de tomada de decisão e participação mobilizam, uns contra os outros, os recursos do Estado constitucional.

O que percebemos, portanto, é que as mudanças na sociedade promovem um processo de inovação autônomo que, de forma ampla e solta, modifica a estrutura social. "Designa uma fase no desenvolvimento da sociedade moderna, em que os riscos sociais, políticos, econômicos e individuais tendem cada vez mais a escapar das instituições para o controle e a proteção da sociedade industrial” (Beck, 2007, p. 15).

A partir dessa noção, percebemos que, na realidade dos catadores de materiais recicláveis associados de Goiânia, as associações e cooperativas podem aqui ser tomadas como uma nova forma de mobilização política, no sentido do que Beck nomeou. Um verdadeiro processo de reinvenção da política, a partir das contingências, complexidades e incertezas advindas com a modernidade tardia. Nela, percebe-se a emergência de uma forma alternativa de se lutar pelo reconhecimento social, pela valorização da identidade do grupo, mediante a criação de oportunidades para que os mesmos se façam ouvir e tenham participação na sociedade. Sinaliza uma tentativa de reação, não apenas no intuito de superar adversidades para o crescimento econômico da atividade de catação, mas - ao mesmo tempo e especialmente - no intuito de superar a exclusão e obter reconhecimento social, por meio da construção de espaços institucionais e simbólicos que promovam identidade e dignidade de grupo aos catadores.

Para conhecer a fundo essa realidade, foi realizado um levantamento de informações de caráter qualitativo ${ }^{2}$ em quatro associações/cooperativas de Goiânia, a A Ambiental, Coper-rama, Coopermas e Beija-Flor. E o que se percebeu foi que os catadores de materiais recicláveis associados de Goiânia buscam superar a exclusão e obter reconhecimento social a partir da união do grupo em 'empresas' democraticamente geridas, a partir dos preceitos da economia solidária, visando ao fortalecimento econômico dos catadores organizados, à promoção de sua diferenciação em relação aos catadores desorganizados e a sua aceitação frente à sociedade formal.

Coutinho (2004), em visão similar, considera que, apesar desta alternativa não poder ser considerada emancipatória e de rompimento com o capitalismo, ela afirma-se como uma "estratégia de resistência e sobrevivência". Estratégia esta que parece ser usada não apenas pelos catadores de materiais recicláveis, mas por diversos grupos. Dados do Ministério do Desenvolvimento Social e Combate à Fome (MDS, 2008) sugerem que entre 2003 e 2007 foram criados quase oito mil empreendimentos econômico-solidários, baseados nos preceitos da economia solidária, com visões de cooperação e contrapostos, em essência, ao modelo da competição capitalista.

Além de ser uma tentativa emancipatória, em termos de formação de identidade, as cooperativas e associações, mais do que um mero agrupamento de pessoas, codificam a possibilidade de distinção entre o catador associado e o de rua. Ao passo que os primeiros são considerados organizados, limpos e trabalhadores, os segundos são vistos como desorga-

2 A proposta para coleta das informações se baseou em metodologia qualitativa, valendo-se de técnicas como etnografia, observação direta e entrevistas em profundidade. Desse modo, acreditou-se ser possível conhecer melhor o dia a dia dos catadores, sua produção simbólica e os significados subjetivos interiores dos agentes. Ao todo, foram realizadas 15 visitas às associações e 13 entrevistas em profundidade. Os catadores entrevistados foram de ambos os sexos, com idades entre 23 e 60 anos.

Em se tratando do perfil das associações estudadas, a Beija-Flor é formada, em sua maioria, por migrantes de outras regiões do estado ou do país, pobres, analfabetos ou semianalfabetos, jovens (média de idade não ultrapassa os 27 anos) e com pouco ou nenhum contato com a família. Alguns são ex-dependentes de drogas e ex-presidiários. A formação da associação se deu na intenção de garantir renda fixa e estável aos catadores, melhorar sua qualidade de vida e ainda para divulgar para toda a sociedade a necessidade de se proteger o meio ambiente e a própria sociedade dos males e perigos provenientes dos desgastes ecológicos de nosso tempo. Na Coper-rama, o perfil continua sendo de membros com baixa escolaridade e renda, contudo se diferem da anterior por não serem migrantes recentes, e por manterem laços frequentes de relacionamento com suas famílias e vizinhos. Formaram a associação com o intuito de prover renda fixa ou complementar às famílias da região do setor Jardim Curitiba III. Na Coopermas, associação piloto do Programa Goiânia Coleta Seletiva, o perfil dos associados é em sua maioria de migrantes, jovens, que estão na catação por falta de opção: não encontraram 'emprego melhor'. Além disso, grande parte é semianalfabeta. Formaram o grupo com a intenção de que unidos pudessem coletar mais resíduos e gerar valor ao material coletado, além de se sentirem mais valorizados como pessoas. Por último, temos a A Ambiental, no Conjunto Itatiaia, que tem estrutura diferente das demais associações visitadas. Seus membros não recolhem materiais recicláveis diretamente nas ruas, como fazem os outros grupos. Recebem doações dos moradores da região e de empresas parceiras. Não catam nas ruas. O diferencial desta associação é a vontade de mudar o mundo à sua volta, e não apenas a percepção dos moradores do Conjunto Itatiaia. Seus membros querem levar para além de seu bairro a percepção de que, quando o lixo não vai parar no lugar adequado, todo o mundo sofre as consequências. 
nizados, sujos e, em sua maioria, marginais. E isso se dá tanto na percepção dos catadores quanto da própria sociedade.

Pertencer a uma cooperativa/associação é elemento capaz de promover a distinção entre o grupo de catadores de materiais recicláveis: enquanto o associado se vê como trabalhador, o catador de rua passa a percepção de ser uma pessoa tentando justificar um pedido de esmola. Se considerarmos a visão de Goffman, podemos ir ainda mais longe: a associação/ cooperativa atua como um símbolo de status para o catador associado, isto é, tem a pretensão especial de dar prestígio e garantir posição social ao catador. E isso se dá porque o modelo identitário desejado é contraposto a antigos modelos e aos estereótipos, estigmas e rótulos, visando superar a injustiça simbólica a que se julgam submetidos os catadores associados. Além disso, quanto mais os catadores se organizam em grupos, mais afastados da rua desenvolvem as atividades de catação e separação do material para reciclagem. Quanto mais organizada a associação/cooperativa, maior a presença de elementos que auxiliam no processo de coleta, como, por exemplo, caminhão da prefeitura, caminhões próprios, parcerias com empresas, que permitem aos catadores não irem às ruas recolher resíduos.

Deixar de frequentar a rua, mais do que evitar desgastes, resulta em representação bastante significativa para os catadores associados. A rua é o lugar onde vivem e trabalham os excluídos (Bursztyn, 2003). É o local de quem vive a "desafiliação" (Gomes, 2000), isto é, o isolamento das relações sociais, de quem depende do mercado informal, de catar papel, vigiar carro e da velha condição de mendigo.

Além disso, a sociedade trata de forma diferenciada o catador organizado, visto como um 'catador limpo, livre de vícios e sério', mesmo que isso não signifique sua inclusão na sociedade formal. Esta percepção está ligada ao reconhecimento de que seu lugar não é a rua, ali não é sua moradia. Ele está apenas de passagem, apenas para coletar a matéria-prima necessária a seu trabalho.

Ainda tratando de associação/cooperativa, a existência de ritos de iniciação na catação organizada, seja por meio da averiguação de antecedentes criminais e da proibição do uso de álcool e drogas entre seus membros, seja pela existência de laços de parentesco e amizade, representa uma tentativa de diferenciação para os próprios catadores e para a sociedade, entre os 'bons catadores e os ruins', os limpos e os sujos, os organizados e os desorganizados. Este rito dá à associação/cooperativa a chance de zelar por sua imagem frente à sociedade, dizendo que seus membros não são marginais, que seu ambiente é seguro e diferenciado. Estimula ainda o significado de formação da identidade pela diferença. Ao negar os valores que não quer para si, contrapõe um modelo identitário desejado a modelos abominados e a estereótipos: promove seu status e sua diferença (símbolos de prestígio) ao mesmo tempo em que estigmatiza ainda mais a imagem da qual quer se livrar, despertando a atenção para a discrepância entre os grupos (símbolos de estigma). Ao passo que o catador associado luta para demonstrar que tem ficha limpa, que não tem problemas com a polícia, o catador de rua é visto pela sociedade como um marginal.

Estes ritos, de acordo com as propostas de Beck e Bauman, demonstram uma tentativa dos excluídos de se fazer pertencer, de ser, se não igual, próximo ao perfil dos incluídos, lembrando que ser incluído representa, no contexto da modernidade tardia, um dos principais elementos impulsionadores da luta pela construção da identidade de grupos que ganham visibilidade nas sociedades que fazem a transição do século XX para o XXI.

Analisando este aspecto apoiados na visão de Goffman, podemos considerar os ritos de iniciação como símbolos desidentificadores ${ }^{3}$, que têm a função de lançar uma nova pretensão sobre o grupo e gerar dúvidas sobre a validade da identidade virtual a que estão sujeitos. Já considerando a ótica de Fraser e o dilema da redistribuição/reconhecimento, estes ritos representam parte da luta pela redistribuição simbólica da pesada carga de discriminação e desrespeito a que o grupo está sujeito.

Os grupos dos catadores, particularizados pela dureza das condições de trabalho e sobrevivência e pela convivência com agudos preconceitos, ilustram de maneira especial o dilema da redistribuição/reconhecimento. Nos termos estruturados por Fraser, o primeiro aspecto desse dilema aparece preenchido pela exploração e marginalização econômica dos catadores e o segundo aspecto, simultâneo, por uma pesada carga de discriminação e desrespeito a várias condições que os qualificam como grupo social portador de dignidade, aspirações e desejos específicos de distinção.

Para a autora, a solução para este tipo de problemas pode estar na reestruturação político-econômica

3 Para Goffman (1988), os símbolos podem ser efêmeros ou institucionalizados como canais de informações. Estes últimos podem transmitir três tipos de mensagens sociais, a saber: a primeira diz respeito aos símbolos de prestígio, que são reivindicações de status, honra ou posição social, a segunda refere-se aos símbolos de estigma que despertam a atenção sobre a discrepância de identidade, como, por exemplo, uma palavra pronunciada de maneira errada, marcas de uma tentativa de suicídio no pulso etc. e por último os símbolos desidentificadores, que visam quebrar uma imagem de forma coerente numa nova direção desejada pelo ator. Para isso, busca não só estabelecer uma nova pretensão como também lançar dúvidas sobre a validade da identidade virtual. 
e/ou na mudança cultural ou simbólica. Podem, inclusive, envolver transformações mais radicais, como as modificações nos "padrões sociais de representação, interpretação e comunicação, a fim de alterar todas as percepções de individualidade" (Fraser, 2001, p. 252).

Nos casos das quatro associações estudadas, a solução para o dilema da redistribuição/reconhecimento é mútua, ocorre no aspecto econômico, com a intenção de formarem as associações e cooperativas onde buscam ter maior poder financeiro para negociar o volume de resíduos com a indústria, e, no simbólico, a partir da forma como denominam o lixo. Para eles, lixo é sinônimo de resíduo que pode ser reaproveitado e não algo inútil, que não tem finalidade.

Compartilhando a visão de Lash e estendendo a compreensão até aqui esboçada, observamos que a realidade dos catadores de materiais recicláveis está sujeita a regras inovadoras de inclusão e de exclusão como grupo social (Lash apud Beck, 2007). Nesse aspecto, o uniforme e o crachá que alguns passam a usar no trabalho exercem função fundamental. Ambos imprimem fortes significados na diferenciação do catador organizado para o catador de rua: na visão dos primeiros, esse vestuário converte-se em símbolo que permite à sociedade formal traduzir a diferença entre o primeiro e o segundo, entre quem é organizado e quem é desorganizado, entre quem passa a impressão de 'andar na linha' e quem é visto como marginal. Atuam como senhas de integração ou inclusão, capazes de permitir ao catador associado o acesso a ambientes típicos da sociedade de consumo, como lojas e shoppings centers, transporte público etc.

Estes elementos podem ser considerados estímulos para a formação da identidade pela diferença. Ao usarem o uniforme e o crachá, os catadores associados negam os valores que não querem para si e criam mecanismos de contraposição entre o modelo identitário desejado e estereótipos dos quais querem se ver livres.

Outro elemento considerável na análise da identidade dos catadores de materiais recicláveis associados é o fato de os catadores considerarem sua atividade uma ocupação provisória. 'Estão' catadores, não 'são' catadores. Durante o trabalho de campo, pôde-se perceber que, para muitos entrevistados, ser catador é um estágio que pode durar enquanto não se encontram outras opções de sobrevivência. Para Gesser e Zeni, essa percepção vincula-se ao fato de a catação ser considerada muito mais uma fonte de garantir trabalho e renda que um movimento de consciência ambiental ou uma escolha real e legítima da profissão (Gesser; Zeni, 2004). Além disso, a atividade da catação, como levantam várias pesquisas, está ligada especialmente à falta de opção dos catadores no mercado, causada pela diminuição das possibilidades de emprego e pelo crescimento dos riscos ambientais. Para Araújo e Silva (2008), as crescentes exigências para o acesso ao mercado formal e a am- pliação do desemprego são os responsáveis por levar um número cada vez maior de pessoas à catação de recicláveis. Já Bursztyn acredita que, além dos fatores mencionados, há ainda a degradação das condições de vida de uma boa parcela da população, pela lógica econômica vigente, que transforma uma série de trabalhadores desempregados em pessoas "desnecessárias" ao circuito econômico e delineia novas formas de miséria: os "novos pobres", que caem dos patamares de pobreza para a miséria, perdem qualquer função produtiva e para sobreviver acabam se inserindo no sistema de forma marginal. Fora tudo isso, ainda são discriminados social e culturalmente, vistos como socialmente ameaçantes (Burstyn, 2003).

Em vista desse quadro negativo, podemos compreender a ambiguidade ou oscilação identitária daqueles que se apresentam como catadores apenas durante a execução do trabalho, no período do expediente. Neste caso, ao terminar sua catação, o catador elimina todas as demonstrações que o fazem estar catador: sujeira das roupas, falta de vaidade, entre outros. Ao sair da situação de trabalho e chegar em casa, ele se reveste de outros referenciais simbólicos: andam com roupas limpas, de banho tomado, cabelos penteados, usam maquiagem e acessórios, se mulheres. Em nada recordam o aspecto e o cheiro de sujeira de quando estão em contato com os materiais recicláveis. A mesma situação é observada quando existe a necessidade de se ter contato com outras pessoas, fora do ambiente de trabalho.

O que este aspecto demonstra, com base nas explicações de Coutinho, é que este modelo de trabalho, em vez de ser considerado uma profissão, está atrelado diretamente à "possibilidade de intermediar o atendimento às necessidades imediatas da sobrevivência [...] e totalmente investido de conotação econômica" (Coutinho, 2004), afetando, inclusive, a formação dos processos identitários dos trabalhadores.

Como mencionado por Sennet, o capitalismo nos dias de hoje, com seu trabalho flexível, temporário, terceirizado, com ênfase no curto prazo, características presentes também no universo dos agentes estudados, diminui as possibilidades de as pessoas construírem uma narrativa coerente para suas vidas valendo-se das experiências profissionais. As características do trabalho da sociedade de risco (precariedade, vulnerabilidade, fragmentação) impõem dificuldades ao processamento de identificações pelo intermédio da profissão e, consequentemente, a construção das identidades profissionais. Há a limitação das possibilidades de estabelecimento de vínculos interpessoais com o fazer, e, com isso, são reduzidas as probabilidades de identificação com os outros e com o trabalho, ao menos na perspectiva da continuidade (Sennet, 2001).

Este aspecto também pode ser entendido pela visão de Bauman segundo a qual temos, neste gru- 
po, um exemplo de identidade líquida, isto é, o pertencer e a identidade não são marcados pela solidez nem garantidos para toda a vida. Pelo contrário, tornam-se negociáveis e revogáveis, frágeis, fáceis de entrar e abandonar, sobretudo pelo próprio modo de se ser e de viver dos catadores (catação como falta de outra opção para sobrevivência, migração, preconceito e estigma).

Um outro aspecto simbólico aqui realçado, capaz de influenciar na formação da identidade dos catadores, conduz para o papel do líder do grupo, especialmente se considerarmos que, após os anos 1980, com o enfraquecimento e a fragmentação das identidades sociais e políticas, perdem força os modelos de representação tradicionais.

Isso quer dizer que, desse período em diante, os modelos de representação até então existentes são questionados, compondo-se "a imagem de uma sociedade que carece de uma imagem de si como unidade, uma sociedade sem vértice nem centro, um sistema de porta-voz e sem representação interna, [uma] sociedade polimorfa" (Gallil apud Novaro, 1995, p. 85). Com isso, fortalecem-se as solidariedades locais e as demandas pontuais, a convivência de tendências a atividades políticas não-institucionais e o desaparecimento de atores sociais capazes de encarnar interesses gerais e de suportar o passar do tempo (Novaro, 1995). É um período que marca a fragilização de identidades coletivas em geral, causadas, na visão de Beck, entre outros motivos, pela emergência dos movimentos subpolíticos.

A esses líderes, então, cabe não apenas agregar e expressar interesses, mas um ato de 'criação de um público', a partir de sua legitimidade. Representar se torna sinônimo de personificar, de dar forma ao representável. O líder se torna, portanto, o canal de identificação, sem o qual os liderados podem se desinteressar e despolitizar, o símbolo maior das qualidades e habilidades do grupo (Novaro, 1995).

Em aspectos decisivos, esse papel de conferir unidade ao grupo mediante de um discurso propiciador de 'auto-imagem' e 'representação interna', tem sido característico nas lideranças das associações pesquisadas. Percebe-se, na maioria dos casos estudados, que os líderes servem como fontes de informações e inspiração para os respectivos associados, direcionam as decisões a serem tomadas por expressarem confiança e representarem instrumentos de coesão grupal: pelo conhecimento e respeito que detêm, mantêm a unidade em relação à formação das associações/cooperativas e da independência econômica. É o caso de cooperativas/associações como a Beija-Flor e a A Ambiental.

Na primeira, o formador da cooperativa, principal liderança ali presente, mesmo não sendo o seu presidente atual, detém a credibilidade dos cooperados por sua história de vida, por seus contatos e suas habilidades pessoais. Apesar de ser analfabeto, detém vasto conhecimento sobre a área da catação, mantém contato com autoridades na Prefeitura de Goiânia, órgãos ligados ao lixo, como a Companhia Municipal de Urbanização (Comurg), movimentos nacional e local dos catadores, além de entidades como Banco do Brasil e Universidade Federal de Goiás.

Já no caso da A Ambiental, a líder da associação é uma mulher que possui formação Superior, morou nos Estados Unidos, mas, quando voltou, não conseguiu entrar no mercado formal de trabalho. Como não encontrou oportunidades que atendiam às suas expectativas, influenciada pela mãe, acabou por vislumbrar no universo da reciclagem uma oportunidade de se tornar empresária, dona de seu próprio negócio, de seu tempo e dinheiro. Por ter conhecimento técnico superior aos demais, serve de inspiração para os associados.

Por outro lado, naquela entidade em que inexiste uma liderança de peso, mesmo que legítima, situação contrária é percebida. Vários associados parecem desestimulados pelo negócio da catação organizada. Críticas, questionamentos sobre as direções tomadas pela presidência e alta direção, rixas e discussões internas são frequentes, formando um ambiente de desunião e que incentiva os associados a apegarem-se a interesses particulares. É o caso da Coopermas. Durante uma das visitas às associações, foi presenciado um fato ilustrativo da situação. Em reunião para definir novas regras para constar do estatuto, vários associados se levantaram, protestaram, acirraram os ânimos dos demais presentes, questionaram o papel do presidente e da diretoria de uma das associações, deram as costas e saíram. Aos que ficaram, o clima de insegurança não permitiu dar continuidade à organização do documento.

Por último, vale a pena mencionar que, de acordo com as observações feitas, os modelos de liderança mais fortes, isto é, com maior credibilidade junto aos cooperados, foram responsáveis pelos desenvolvimentos mais completos de transformação das associações em cooperativas. A presença de lideranças desta natureza proporcionou aos grupos decidirem mais rapidamente sobre a composição da diretoria, formação dos estatutos, aprovação dos mesmos, além de definições burocráticas, como definições quanto à identidade visual (marca, uniformes, crachás, papelaria etc), aprovações perante os órgãos oficiais, entre outros. Esta é a realidade da Beija-Flor e da A Ambiental.

No caso de associações com líderes fracos, a pesquisa demonstra que a falta de uma liderança que tenha credibilidade e estimule os associados faz dos processos internos procedimentos morosos e cheio de temores quanto a possíveis perdas financeiras individuais. Além disso, nota-se nestas associações maior preocupação com interesses individuais, tais quais remuneração individual e possibilidade de perdas financeiras próprias. Essa é uma marca da Coopermas.

Sobre a construção da identidade do grupo de catadores de materiais recicláveis associados de Goiânia, podemos mencionar ainda alguns outros aspectos que 
afetam diretamente o processo. São eles a representação do lixo para o grupo e o preconceito a que estão sujeitos.

Com relação à representação do lixo, percebemos que, num contexto de abundância, de consumo e de risco, os sentidos dados ao lixo não se reduzem a um montante de objetos inúteis e descartáveis. Para o grupo dos catadores de materiais recicláveis, especificamente, o lixo ganha um novo significado, torna-se sinônimo de sobrevivência. É, a um só tempo, destino e fonte de materiais que podem ser transformados em dinheiro e fonte de renda, garantindo o próprio sustento e o dos familiares.

Isso acontece em razão de, pelo menos, três fatores que ganham visibilidade na contemporaneidade, quais sejam: o crescimento do colapso ambiental, a falta de oportunidades no mercado de trabalho formal e, consequentemente, a necessidade de obtenção de renda por vias marginais, tendo em vista a baixa escolaridade e experiência dos catadores.

Sem outra opção de trabalho, os catadores transformam a catação de lixo em uma forma de se sustentarem e, para alguns, até mais que isso, "uma profissão como qualquer outra".

Neste caso, faz-se relevante registrar que o lixo precisa ser legitimado para o próprio catador e deste para a sociedade. Para isso, lixo e catação são apresentados com base nas vantagens e nos benefícios que oferecem para a vida da sociedade. Os catadores, em diferentes situações discursivas, insistem na condição distintiva da atividade, de contribuir para a redução dos riscos ambientais. Além disso, o lixo deixa de, apenas, representar rejeito que o caminhão de lixo leva embora, digno de humilhação para quem dele faz uso, para ser mais fortemente percebido como resíduo, como material reciclável, isto é, aquilo que "ainda pode ser aproveitado", que "tem valor comercial", "um negócio", uma "forma de se alcançar a estabilidade", "um trabalho independente". São duas visões que coexistem no imaginário dos catadores, de maneira conflitiva, embora não-excludente, ambas fornecendo conteúdos e motivos para alimentar a contraditória autoimagem e a identidade desse grupo social.

Por fim, uma das questões mais marcantes no estudo da identidade do grupo de catadores associados é o preconceito. Há o receio constante da marginalização pelo olhar do outro, de fazer parte de um grupo estigmatizado. Outras formas de preconceito também são relatadas, como o olhar de superioridade de quem os vê mexendo no lixo e aquele vindo de pessoas próximas. Para exemplificar o primeiro caso, há a fala de uma das catadoras entrevistadas, "muitas vezes somos tratados como se fossemos o próprio lixo e isso machuca muito". Na segunda forma de preconceito, uma catadora expôs que sua irmã, ao saber que ela estava catando lixo, humilhou-a, dizendo que ela era uma vergonha para a família, que não poderia expor a família a tamanho constrangimento. "A minha irmã me disse um dia que eu era a vergonha da família. Como um membro da família podia mexer com lixo?"

Há ainda os relatos relacionados aos vizinhos. Como boa parte dos catadores de material reciclável entrevistados armazena materiais nos próprios quintais, há o medo de que a dengue e doenças provindas de ratos e baratas atinjam as pessoas ao redor. Neste caso, são várias as narrativas que contam como os vizinhos, pelo medo, acabam insultando os catadores, chamando-os de sujos, porcos, inferiores e de pessoas que vivem no submundo.

Por último, há o receio de serem considerados lixeiros. Para os catadores associados, o lixeiro é sempre o outro, ou o que trabalha catando lixo nas ruas, com o caminhão da prefeitura, ou com a varrição, ou, ainda, aquele que produz o lixo, mas nunca o catador de material reciclável. "Não sou catador de lixo, sou catador de material reciclável".

Tratando-se de preconceito, o movimento de consciência dos estudados nos permite ainda perceber que o universo dos catadores não envolve apenas discriminação. Ele também dá lugar à estigmatização, pelo preconceito interno do próprio catador para consigo. As entrevistas demonstram que estes agentes não querem que seus filhos sigam o mesmo caminho. Quando perguntados sobre quais profissões gostariam que seus filhos seguissem, se esperam que eles trilhem os mesmos caminhos deles na catação, vários foram os entrevistados que demonstraram não desejar que seus filhos sejam catadores. Os argumentos para isso estão relacionados sobretudo às dificuldades dadas pelo preconceito. Ao mesmo tempo, dizem querer que os filhos sejam alguém na vida.

Paralelo aos preconceitos e estigmas demonstrados até aqui, há o estigma do próprio catador para com os outros catadores. Isso acontece particularmente com relação ao catador de cooperativa $x$ o catador de rua. Nota-se no discurso dos entrevistados uma grande necessidade destes de se diferenciarem dos catadores considerados marginais, dos renegados pela sociedade. Não querem ser confundidos com a imagem negativa do catador de rua, ligada ao universo do álcool, das drogas e de crimes. E neste aspecto o associativismo é a grande arma para diferenciá-los dos demais.

$\mathrm{O}$ entendimento dessas questões requer voltarmos ao pensamento de Goffman sobre a autocontradição básica existente em indivíduos estigmatizados. Para ele, grupos com atributos depreciativos, como o referido, acreditam em seus sentimentos mais profundos, que são pessoas normais, seres humanos como outros quaisquer, criaturas que merecem "um destino agradável e uma oportunidade legítima" (Goffman, 1988 , p. 16), embora se definam como marginalizados. É difícil, portanto, para eles, aceitarem as marginalizações e imposições dos 'normais'.

Para tentar combater estas sensações a que estão sujeitos, buscam corrigir indiretamente o atributo depreciativo (não conseguem livrar-se diretamente dele já que 
não encontram outra opção de renda), ora escondendo ou eliminando os símbolos de estigma, “... não quero mais que minha mãe cate...", ora pelo uso de símbolos desidentificadores, “... mas a gente sempre deixa tudo limpinho, organizadinho...”, ora pela apresentação dos signos de seu estigma como signos de um outro atributo que seja um estigma menos significativo, "Não sou catador de lixo, sou catador de materiais recicláveis". Agem ainda a partir de uma estratificação autoevidente (Goffman, 1988), em que estratificam seus pares conforme o grau de visibilidade e imposição dos estigmas.

Finalmente, podemos observar que o preconceito leva o grupo de catadores de materiais recicláveis a uma situação em que há ambivalência de identidade (Goffman, 1988, p. 118). Por mais que tentem se afastar de seu grupo, apoiando as normas da sociedade mais ampla, "sua identificação psicológica e social com os transgressores os mantêm unidos ao que repelem, transformando a repulsa em vergonha e, posteriormente, convertendo a própria vergonha em algo de que se sente envergonhado. Em resumo, não pode nem aceitar o seu grupo nem abandoná-lo" (Goffman, 1988, p. 118). "Por mais que eu sinta vergonha do que faça, eu não tenho outra forma de sobreviver".

\section{Considerações finais}

Este artigo teve como objetivo apresentar resultados obtidos com a pesquisa Risco e Consumo: a Construção da Identidade a partir do Lixo, que buscou compreender como os grupos formados com base no contexto da sociedade de risco, de novas formas de vida individuais e coletivas e de novas instituições, configuram suas identidades distinguindo-se como grupos sociais legítimos. Para tanto, baseou-se num universo específico, os catadores de materiais recicláveis associados de Goiânia.

As informações apresentadas permitiram conduzir algumas caracterizações empíricas e compreensões sobre esse grupo, que o contextualizam como formação social típica da modernidade tardia, etapa regida pelas lógicas simultâneas da sociedade de risco, dos impulsos ao consumo e da busca de distinção por parte de seus segmentos. Como agentes sociais desse contexto, os catadores experimentam processos contraditórios e ambivalentes na constituição de uma identidade social específica.

Em primeiro lugar, a construção identitária dos trabalhadores na catação traduz uma dura realidade de luta pela sobrevivência em condições de quase completa marginalidade e sujeitos a toda sorte de discriminações. A essa situação adversa, porém, eles conseguem incorporar significados que lhes são próprios e que formulam a partir da coexistência com o mundo externo e, mais ainda, a partir do experimento associativo.

Em segundo lugar, o experimento associativo é a forma que os catadores conseguem encontrar para se deferem como força de trabalho e se integram ao mercado formal. Ao se organizarem em associações e cooperativas, os catadores de materiais recicláveis agregam-se em grupo, formam lideranças e símbolos de distinção face as situações e imagens que desejam superar. Alteram, enfim, as bases de sua sobrevivência, a sua relação com o lixo e a sua própria existência na sociedade de consumo.

$\mathrm{O}$ artigo também permitiu sinalizar que a identidade do grupo de catadores de materiais recicláveis de Goiânia se encontra em formação, submetida a complexas dinâmicas subjetivas, marcadas por processos não-lineares, repletos de contradições, tensões e fragilidades. Tais dinâmicas, ademais, mostram-se ambivalentes e não se realizam como em outras identidades profissionais. É típico dessas dinâmicas que os mesmos fatores que marginalizam também integram o grupo. Assim, ao mesmo tempo em que o lixo é fator marginalizante, já que ali são encontrados os rejeitos da sociedade, ele é também elemento que viabiliza um processo de ressignificação por parte do grupo, capaz de integrar pessoas consideradas excluídas do mercado formal, visto ser esta sua única opção de sobrevivência.

Ambivalência semelhante foi encontrada com relação aos sentimentos de preconceito e estigma. Se, por um lado, os catadores associados são marginalizados quando possuem imagem deteriorada diante da sociedade, eles replicam este mesmo sentimento dirigindo-o a quem consideram em situação mais degradada que a sua ou anômica. Reproduzem o preconceito a que estão sujeitos, numa tentativa de promover distinções dentro do próprio grupo.

\section{Referências}

ARAÚJO, A.; SILVA, L. Diagnóstico dos catadores de recicláveis do município de Goiânia. Monografia (TCC) - Universidade Federal de Goiás, Goiânia, 2008.

BAUMAN, Z. Identidade. Rio de Janeiro: Jorge Zahar, 2005a. BAUMAN, Z. Vidas desperdiçadas. Rio de Janeiro: Jorge Zahar, 2005b.

BAUMAN, Z. Vida líquida. Rio de Janeiro: Jorge Zahar, 2007.

BAUMAN, Z. Consuming life. Londres: Sage, 2001. Disponível em: <http://www.joc.sagepub.com>. Acesso em: 14 fev. 2008.

BECK, U. World risk society. Malden. USA: Polity Press, 2007. BURSZTYN, M. (Org.). No meio da rua: nômades, excluídos e viradores. Rio de Janeiro: Garamond, 2003.

COUTINHO, M. C. O lixo como estratégia de sobrevivência: a psicologia nas organizações solidárias, 2004. Disponível em 
<http://www.extensio.ufsc.br/20042/Direitos_Humanos_ CFH_Maria_Chalfim.pdf>. Acesso em: 06 out. 2008.

FRASER, N. Da redistribuição ao reconhecimento? Dilemas da justiça na era pós-socialista. In: SOUZA, J. Democracia hoje: novos desafios para a teoria democrática contemporânea. Brasília: Ed. da UnB, 2001.

GESSER, M.; ZENI, A. B. A educação ambiental como uma possibilidade de promover cidadania aos catadores de materiais recicláveis. 2004. Disponível em <http://www.ufmg.br/congrext/ Meio/Meio35.pdf>. Acesso em: 22 jul. 2008.

GOFFMAN, E. A representação do eu na vida cotidiana. Petrópolis: Vozes, 1985.

GOFFMAN, E. Estigma: notas sobre a manipulação da identidade deteriorada. Rio de Janeiro: Guanabara, 1988.
GOMES, W. População adulta de rua: a perversa exclusão social. 2000. Disponível em <http://www.redadultosmayores. com.ar/buscador/files/DCRAM014.pdf>. Acesso em: 17 nov. 2008.

MDS: Ministério do Desenvolvimento Social e Combate à Fome. Pesquisa nacional sobre a população em situação de rua. 2008. Disponível em < http://www.mds.gov.br/noticias/ maioria-da-populacao-em-situacao-de-rua-trabalha-e-tem-familiares-na-cidade-onde-vive $>$. Acesso em: 28 dez. 2008. NOVARO, M. O debate contemporâneo sobre a representação política. Novos Estudos, n. 42, São Paulo, Cebrap, p. 77-90, 1995.

SENNET, R. A corrosão do caráter: consequências pessoais do trabalho no novo capitalismo. São Paulo: Record, 2001.

\title{
Trash, identity and work: the identity construction of recyclable material collectors associated of Goiania
}

\begin{abstract}
Nowadays, faced with labor market exclusion, there are several survival strategies adopted by social groups with lower qualifications. Among those who find themselves in this situation, we can mention the reality of recyclable material collectors. For this group which lives of garbage cans - places where we can find the main and most abundant goods of our time, the drop of consumption represent the location of the excluded and rejected, a place where nobody wants to be, a particular situation is outlined. It is there that these workers, subject to a deteriorating social identity, find a legitimate way to survive, to build their identity and crave social recognition. This paper describes how this process has been established, and how this group in particular, has been trying from collective formations, to promote its distinction as a legitimate social group.
\end{abstract}

Keywords: identity formation, associations, trash, work, social groups.

\section{De basura, el trabajo y la identidad: la construcción de la identidad de los recolectores de material reciclable asociados en Goiânia}

\begin{abstract}
Resumen
En la actualidad, frente a um mercado laboral exclugente, hay muchas estrategias de supervivencia adoptadas por los grupos sociales con bajas calificaciones profesionales. Entre los que se encuentran en esta situación, podemos mencionar la realidad de los recolectores de materiales reciclables. Para este grupo, que vive en las latas de basura, donde se encuentran los productos más importantes y más abundante de nuestro tiempo, los descartes de consumo, pero al mismo tiempo, representa la ubicación de los rechazados y excluidos, un lugar donde nadie quiere estar, una situación particular, se describe. Es allí que estos trabajadores están sujetos a un deterioro de la identidad social, es una forma legal para sobrevivir, para construir su identidad y anhelan el reconocimiento social. Este trabajo muestra cómo este proceso se ha establecido, y cómo este grupo en particular, ha tratado las formaciones colectivas, para promover su distinción como un legítimo grupo social.
\end{abstract}

Palabras clave: formación de la identidad; asociación; la basura; el trabajo; los grupos sociales.

Data de recebimento do artigo: 16-11-2010

Data de aprovação do artigo: 22-01-2011 